\title{
Spray Pyrolysis growth of a high figure of merit, nano-crystalline, $p$-type Transparent Conducting Material at low temperature.
}

\author{
L. Farrell, ${ }^{1, \text { a) }}$ E. Norton, ${ }^{1}$ B.J. O'Dowd, ${ }^{1}$ D. Caffrey, ${ }^{1,2}$ I.V. Shvets, ${ }^{1}$ and K. Fleischer ${ }^{1}$ \\ ${ }^{1)}$ School of Physics and Centre for Research on Adaptive Nanostructures and Nanodevices (CRANN), Trinity College, \\ University of Dublin, Dublin 2, Ireland \\ 2) Advanced Materials Bio-Engineering Research Centre (AMBER), Trinity College, University of Dublin, Dublin 2, \\ Ireland
}

(Dated: 10 July 2015)

\begin{abstract}
In this letter we demonstrate a low temperature $\left(\approx 345^{\circ} \mathrm{C}\right)$ growth method for $\mathrm{Cu}$ deficient $\mathrm{CuCrO}_{2}$ performed by spray pyrolysis using metal-organic precursors and a simple air blast nozzle. Smooth films were grown on glass substrates with a highest conductivity of $12 \mathrm{~S} / \mathrm{cm}$. The most conductive samples retain transparencies above $55 \%$ resulting in a figure of merit as high as $350 \mu \mathrm{S}$, which is the best performing $p$-type transparent conducting material grown by solution methods to date. Remarkably despite the nano-crystallinity of the films, properties comparable with crystalline $\mathrm{CuCrO}_{2}$ are observed. No postannealing of the films is required in contrast to previous reports on crystalline material. The low processing temperature of this method means the material can be deposited on flexible substrates. As this is a solution based technique it is more attractive to industry as physical vapour deposition methods are slow and costly in comparison.
\end{abstract}

$p$-type transparent conducting materials (TCMs) are sought after for optoelectronic devices. Currently commercially available $n$-type TCMs, such as indium tin oxide (ITO), possess conductivities as high as $1000 \mathrm{~S} / \mathrm{cm}$ with transparencies greater than $80 \% .{ }^{1}$ Potential applications that require $p$-type materials with similar properties include transparent $p$ - $n$ junctions, which would allow for fully-transparent displays. ${ }^{2}$ Alternatively, they can be used to minimize shunting as hole injection/extraction layers in light-emitting diodes/solar cells. ${ }^{3,4}$ The main interest in this field originated from the potential of the delafossites with the $\mathrm{A}^{1+} \mathrm{B}^{3+} \mathrm{O}_{2}$ lattice structure first highlighted in 1997 when $\mathrm{CuAlO}_{2}$ was reported to exhibit $p$ type conductivity while maintaining high transparency. ${ }^{5}$ Since then the field has extended to other materials such as oxychalcogenides, spinels and $\alpha-\mathrm{Cr}_{2} \mathrm{O}_{3} \cdot{ }^{6-9}$

One of the delafossites, $\mathrm{CuCrO}_{2}$, has shown promise as a $p$-type TCM due to reports of high conductivity when doped with Mg. ${ }^{10}$ However this is typically only achieved by physical vapour deposition (PVD) which is a relatively slow and costly technique in comparison to other depostion methods. $\mathrm{CuCrO}_{2}$ has also been grown by chemical vapour deposition (CVD) using the metal-organic Acetylacetonate (acac) precursors $\mathrm{Cr}(\mathrm{acac})_{3}$ and $\mathrm{Cu}(\mathrm{acac})_{2}$ at $550^{\circ} \mathrm{C}$, resulting in polycrystalline films with conductivity of $0.86 \mathrm{~S} / \mathrm{cm}$ (figure of merit $(\mathrm{FOM}) \approx 45 \mu \mathrm{S}) .{ }^{11}$ Spray pyrolysis $(\mathrm{SP})$ is an inexpensive technique that is suited to depositing films over a large area. Mg-doped films of $\mathrm{CuCrO}_{2}$ have been synthesized by SP using the same acac precursors with the $\mathrm{Mg}(\mathrm{acac})_{2}$ precursor for doping. Only after postannealing at $700^{\circ} \mathrm{C}$ did they achieve conductivities of $0.6-1 \mathrm{~S} / \mathrm{cm} .{ }^{12,13} \mathrm{CuCrO}_{2}: \mathrm{Zn}$ grown by solgel processing show conductivities of around $0.47 \mathrm{~S} / \mathrm{cm}$ after two postannealing steps. ${ }^{14}$ The high temperature required by these methods is a major drawback for using

a)Electronic mail: lefarrel@tcd.ie the material in practical devices.

In this letter SP was used to grow thin $(50-100 \mathrm{~nm}) \mathrm{Cu}$ deficient $\mathrm{CuCrO}_{2}$ films. We demonstrate that there is potential to improve the conductivity of $\mathrm{CuCrO}_{2}$ grown by a single step method without the need for post-annealing or extrinsic doping. Despite their nano-crystallinity the films show high conductivities of $12 \mathrm{~S} / \mathrm{cm}$ without intentional doping. The film growth is also at the favourable lower temperature of $\approx 345^{\circ} \mathrm{C}$ which means it is more suitable for industrial growth processes. This is in contrast to earlier reports of the dependency of the conductivity on higher growth temperatures $\left(>500^{\circ} \mathrm{C}\right)^{15}$, and the requirement of crystallinity to retain $p$-type properties. ${ }^{16}$ This also means that the $\mathrm{Cu}$ deficient nanocrystalline material is compatible with flexible substrates such as polyimides and flexible glass (typically $<400^{\circ} \mathrm{C}$ process temperatures). This is the best performing $p$ type TCM grown by solution methods to date (excluding reports on single-crystal substrates ${ }^{17}$ ), surpassing the previous value of $151 \mu \mathrm{S} .{ }^{18}$ Most importantly it is the facile synthesis, using inexpensive components, that makes this method exceptional.

$\mathrm{Cu}(\mathrm{acac})_{2}$ and $\mathrm{Cr}(\mathrm{acac})_{3}$ precursors were dissolved in $100 \mathrm{ml}$ of methanol solvent (in contrast to the previous choice of isopropanol $^{12,13}$ ) and sprayed with an air blast nozzle (PNR, model 0331) at a rate of $1.7 \mathrm{ml} / \mathrm{min}$ using a mixture of compressed air and nitrogen with an air pressure of $17 \mathrm{l} / \mathrm{min}$ onto heated glass microscope slides. Further details of the growth system are given elsewhere $^{19}$, although for this study the ceramic heater has been replaced with a laboratory hot-plate to allow deposition on larger areas. The $\mathrm{Cr}(\mathrm{acac})_{3}$ concentration was kept constant at $0.025 \mathrm{M}$ while the $\mathrm{Cu}(\text { acac })_{2}$ concentration was approximately $0.01 \mathrm{M}$. An optimum oxygen concentration of $5 \%$ was observed for the best performing films. Heater surface temperature readings during spraying, were taken using a type $\mathrm{K}$ thermocouple (chromel vs alumel) welded to the top of the hot plate. The temper- 


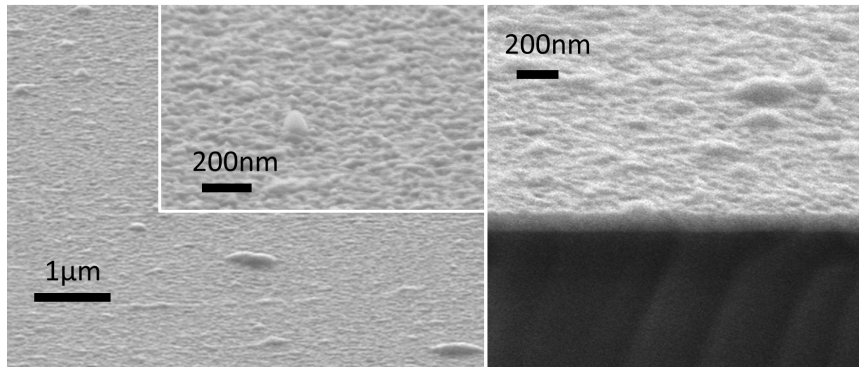

FIG. 1. Scanning electron microscopy (SEM, Carl Zeiss Ultra) showing the morphology of the films at a tilt angle of $11^{\circ}$. The imaging was performed at $5 \mathrm{kV}$.

ature was PID controlled during spray conditions within $\pm 10^{\circ} \mathrm{C}$.

Fig. 1 shows SEM images of the morphology of the films. Films less than $90 \mathrm{~nm}$ are smooth enough (rms: 4-6 nm) that the thickness can be determined from x-ray reflectivity (XRR) measurements. Thicker films are too rough $(>6 \mathrm{~nm})$ to display X-ray interference fringes. In this case the thickness is determined from modelling UV-VIS reflectance measurements. The total UV-VIS transmittance and reflectance of the films were measured with a Perkin Elmer 650S spectrophotometer equipped with an integrating sphere. Electrical conductivity measurements were performed using a linear four point probe geometry with gold coated tips. Seebeck measurements, performed as previously described ${ }^{9}$, confirmed the $p$-type nature of the films. The system was calibrated using chromel wire and an error of $<5 \%$ was observed.

$\mathrm{CuCrO}_{2}$ adopts the delafossite structure which consists of linearly coordinated $\mathrm{Cu}$ atoms in an $\mathrm{O}-\mathrm{Cu}-\mathrm{O}$ dumbbell shape. These are stacked between edge-sharing octahedral layers $\left(\mathrm{CrO}_{6}\right)$ along the c-axis. ${ }^{20} \mathrm{CuCrO}_{2}$ films grown in this report adopt the rhombohedral crystal cell with space group R3-mh. Fig. 2(a) shows an x-ray diffraction (XRD) pattern performed by a Bruker D8 Advance diffractometer using a $\mathrm{Cu} \mathrm{K} \alpha$ source with a double bounce Ge monochromator. The broad glass background has been subtracted from the data. The (012) and (110) diffraction lines of $\mathrm{CuCrO}_{2}$ can be seen as broad peaks. The (101) diffraction line is of lower intensity and may be masked by the broad (012) line. Mixed phases during the synthesis of delafossites have been reported before and alternative phases are shown in Fig. 2(a). ${ }^{21}$ However in this case the presence of both diffraction lines are only consistent with the $\mathrm{CuCrO}_{2}$ crystallographic phase. Using the MAUD software package and the $\mathrm{CuCrO}_{2}$ cif file (PDF number 01-089-6744) the $a$ and $c$ lattice parameters were calculated to be $2.98 \pm 0.05 \AA$ and $17.16 \pm 0.05 \AA$ respectively, which is close to their crystalline values of $2.97 \AA$ and $17.1 \AA$. The average coherent domain size however, was found to be less than $10 \mathrm{~nm}$.

To complement the crystallographic information from $\mathrm{XRD}$, the vibrational modes were measured by MicroRaman spectroscopy in a Renishaw inVia system using a $532 \mathrm{~nm}$ solid state laser in backscattering geometry. Fig. 2(b) shows the Raman signal for the material, which
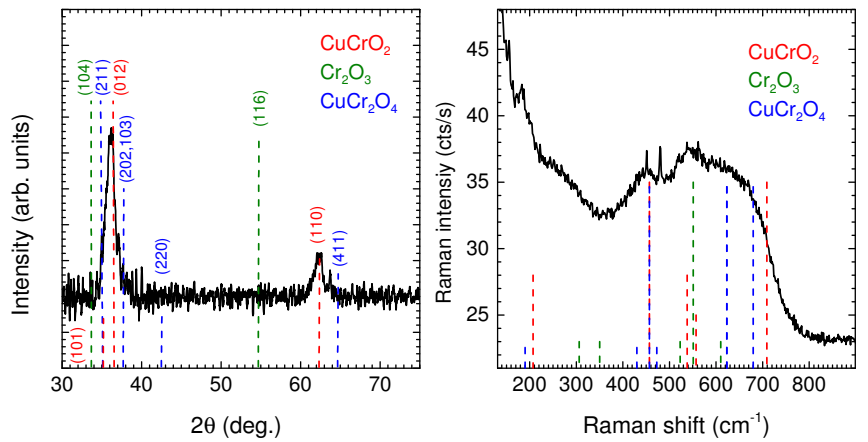

FIG. 2. (a) XRD pattern of the cu-deficient $\mathrm{CuCrO}_{2}$ films, with the XRD diffraction lines indexed for $\mathrm{CuCrO}_{2}, \alpha-\mathrm{Cr}_{2} \mathrm{O}_{3}$ and $\mathrm{CuCr}_{2} \mathrm{O}_{4}$. (b) Raman spectra with the vibrational modes of $\mathrm{CuCrO}_{2}, \alpha-\mathrm{Cr}_{2} \mathrm{O}_{3}$ and $\mathrm{CuCr}_{2} \mathrm{O}_{4}$ highlighted.

is more sensitive to the local bond arrangement, rather than long range order. The Raman modes for crystalline $\mathrm{CuCrO}_{2}$ at $207,454 \mathrm{~cm}^{-1}$ and $703 \mathrm{~cm}^{-1}$ are present, but are very broad and shifted to lower wave numbers. ${ }^{22,23}$ The Raman modes for $\alpha-\mathrm{Cr}_{2} \mathrm{O}_{3}$ and $\mathrm{CuCr}_{2} \mathrm{O}_{4}{ }^{24}$ are also highlighted, but it is difficult to determine their contribution due to the broad nature of the spectra. This confirms the poor crystallinity suggested by the XRD data. The weaker, defect induced $\mathrm{CuCrO}_{2}$ modes around $550 \mathrm{~cm}^{-1}$ are quite pronounced in our sample, illustrating a larger number of $\mathrm{Cr}-\mathrm{O}$ octahedra in the $\mathrm{Cu}$ deficient samples compared to crystalline $\mathrm{CuCrO}_{2}$. A similar enhancement of these defect modes has been previously reported for stressed $\mathrm{CuCrO}_{2}: \mathrm{Mg} .{ }^{23,25}$

To assess the stoichiometry of the films, X-Ray Photoemission Spectroscopy (XPS) measurements were performed on an Omicron Multiprobe XPS system using $\mathrm{Al}$ $\mathrm{K} \alpha$ x-rays $(\mathrm{h} \nu=1486.7 \mathrm{eV})$ with an EA125 U5 analyser. All samples were chemically cleaned in acetone and isopropanol with an ultrasonic bath and sputter-cleaned using an Ar ion gun operated at $500 \mathrm{~V}$ for 10 minutes with a sputter current of $2-3 \mu \mathrm{A}$ (at low voltage to prevent oxygen sputtering) to remove traces of unreacted precursors on the surface. ${ }^{26}$ Fig. 3 shows the XPS spectra of the Cr $2 \mathrm{p}$ and $\mathrm{Cu} 2 \mathrm{p}$ regions respectively, for the highest FOM sample. XPS spectra can differentiate between the two oxidation states of copper, $\mathrm{Cu}^{1+}$ and $\mathrm{Cu}^{2+} .93 .5 \%$ of the $\mathrm{Cu} 2 \mathrm{p}_{3 / 2}$ peak area is consistent with a $\mathrm{Cu}^{+1}$ oxidation state at a binding energy of $932.4 \mathrm{eV}$. Smaller components of $\mathrm{Cu}^{+2}$ at $933.8 \mathrm{eV}$ and hydroxide at $935 \mathrm{eV}$ are present but account for only a few percent of the peak area. Many authors use the presence of the well known shake-up satellite peaks, between $940-945 \mathrm{eV}$, as an indication of the $\mathrm{Cu}^{2+}$ oxidation state which is absent in our spectra. The binding energy of the $\mathrm{Cr} 2 \mathrm{p}_{3 / 2}$ is $576.6 \mathrm{eV}$, indicating a $3^{+}$oxidation state, which is consistent with previous reports for $\mathrm{CuCrO}_{2} \cdot{ }^{27,28}$

The $\mathrm{Cu} /(\mathrm{Cu}+\mathrm{Cr})$ ratio is the atomic ratio defined as the following fraction $\mathrm{Cu} /(\mathrm{Cu}+\mathrm{Cr})^{*} 100$ (as a percentage). A $\mathrm{Cu} /(\mathrm{Cu}+\mathrm{Cr})$ ratio of $50 \%$ would be expected for stoichiometric $\mathrm{CuCrO}_{2}$, while our best performing films are $\mathrm{Cu}$ deficient with $\sim 30-35 \%$ for the $\mathrm{Cu} /(\mathrm{Cu}+\mathrm{Cr})$ ratio. 


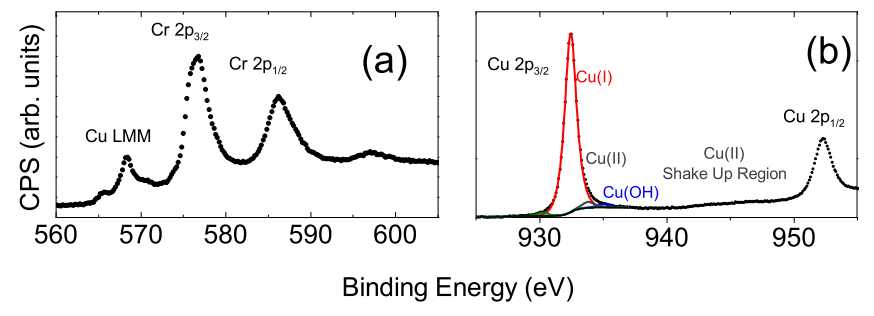

FIG. 3. XPS spectra of the $\mathrm{Cr} 2 \mathrm{p}$ and $\mathrm{Cu} 2 \mathrm{p}$ regions of $\mathrm{CuCrO}_{2}$. Figure 3(a) shows the Cr $2 \mathrm{p}$ peak region is complicated by an Auger peak of copper but the Cr $2 \mathrm{p}_{3 / 2}$ has a binding energy of $576.6 \mathrm{eV}$ which matches reports for $\mathrm{CuCrO}_{2}$. Figure 3(b) shows the $\mathrm{Cu} 2 \mathrm{p}_{3} / 2$ peak is consistent with a $\mathrm{Cu}^{+1}$ oxidation state with a binding energy of $932.4 \mathrm{eV}$, $\mathrm{FWHM}=1.1$. Smaller components of $\mathrm{Cu}^{+2}$ at $933.8 \mathrm{eV}$ and hydroxide at $935 \mathrm{eV}$ are present. The $\mathrm{Cu}$ satellite peaks between $940-945 \mathrm{eV}$ for $\mathrm{Cu}^{2+}$ is notably absent.

The $\mathrm{Cr}: \mathrm{Cu}: \mathrm{O}$ ratio is approximately 1:2:4 which indicates that the atomic ratio is close to the spinel phase of copper chromite $\left(\mathrm{CuCr}_{2} \mathrm{O}_{4}\right)$. However the absence of $\mathrm{Cu}^{2+}$ from the XPS analysis and the high transparency of the material suggest that the material is closer related to $\mathrm{CuCrO}_{2}$ in terms of crystallographic structure and opto-electronic properties. $\mathrm{CuCr}_{2} \mathrm{O}_{4}$ has been found to be very absorbant, even in thin film form. ${ }^{29}$ In order to investigate the ratio throughout the film a sample was argon plasma etched in intervals at a higher voltage of $750 \mathrm{~V}$, taking the atomic ratio at each interval. The etch rate was approximately $0.35 \mathrm{~nm} / \mathrm{min}$. This is shown in Fig. 4. As can be seen the ratios do not vary significantly throughout the film. Due to the nano-crystalline nature of the films a definite assignment of the dominant phase remains difficult, though a $\mathrm{Cu}$ deficient $\mathrm{CuCrO}_{2}$ structure is the most consistent with all of the available data.

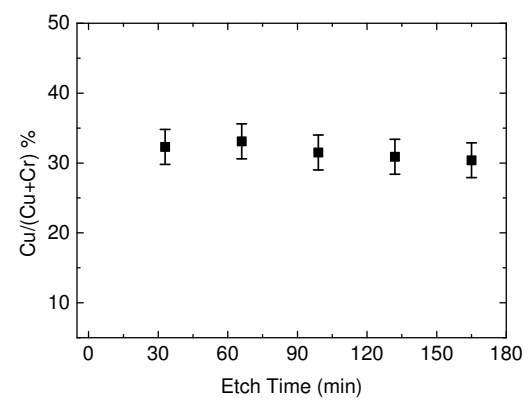

FIG. 4. Depth profiling showing the variation in the $\mathrm{Cu} /(\mathrm{Cu}+\mathrm{Cr})$ ratio.

To compare our results to the literature the FOM was calculated using Eq. 1.

$$
F=\frac{\sigma}{\alpha}=\frac{-1}{R_{\mathrm{sh}} \ln (T+R)}
$$

where $R_{\mathrm{sh}}$ is the sheet resistance, $T$ is the transmittance, $R$ the reflectance, $\sigma$ is the conductivity and $\alpha$ is the absorption coefficient. The $T$ and $R$ values are the average
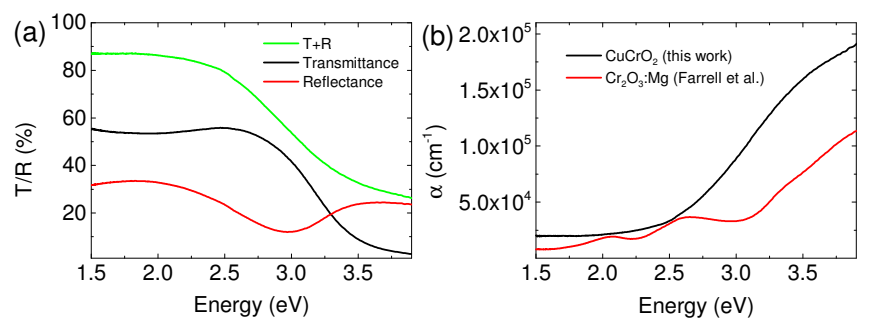

FIG. 5. (a) Transmittance and Reflectance of a $70 \mathrm{~nm}$ film. (b) The absorption spectra of $\mathrm{Cu}$ deficient $\mathrm{CuCrO}_{2}$ is compared to $\alpha-\mathrm{Cr}_{2} \mathrm{O}_{3}: \mathrm{Mg} .{ }^{9}$ All measurements were taken with air as a reference.

of 30 points over the $1.5-3 \mathrm{eV}$ range. $T$ and $R$ data are used to minimize the effect of Fabry-Perot oscillations on the FOM estimation. Fig. 5(a) shows the $T$ and $R$ data for the best performing sample resulting in a FOM of $350 \mu \mathrm{S}$. It was found during screening that both the oxygen partial pressure and temperature affect the performance of the films. There is a narrow temperature range $\left( \pm 3^{\circ} \mathrm{C}\right)$ to obtain the best performing films for a given $\mathrm{Cu} /(\mathrm{Cu}+\mathrm{Cr})$ precursor ratio. This is related to the temperature dependent decomposition rate of the precursors which results in an optimum temperature window. Similarly the decomposition of the precursors is influenced by the presence of oxygen. The absorption spectra of $\mathrm{Cu}$ deficient $\mathrm{CuCrO}_{2}$ is compared to $\alpha-\mathrm{Cr}_{2} \mathrm{O}_{3}: \mathrm{Mg}^{9}$ in Fig. 5(b). The two absorption peaks at 2.1 and $2.6 \mathrm{eV}$ are well known for $\alpha-\mathrm{Cr}_{2} \mathrm{O}_{3}$ and are absent in our films. The conductivity of the films was in the range $4-12 \mathrm{~S} / \mathrm{cm}$ for the samples with the highest FOM. Fig. 6 shows the variation of conductivity with temperature. Above $220 \mathrm{~K}$ the small polaron hopping (SPH) model is used to fit the data and a hopping activation energy $\mathrm{W}$ of $65 \mathrm{meV}$ is calculated, which is comparable to Boltzmann activation energies previously obtained. ${ }^{30}$ At approximately $220 \mathrm{~K}$ there is a discernible change in the slope of the line which indicates a crossover in the conduction mechanism. The inset of Fig. 6 shows how the conductivity varies with temperature using the variable range hopping (VRH) model. The $\mathrm{T}^{-1 / 4}$ dependence at low temperature has been observed previously in $\mathrm{CuCrO}_{2}{ }^{11}, \mathrm{CuAlO}_{2}{ }^{31}$ and $\mathrm{CuCrO}_{2}: \mathrm{Mg}^{32}$ and is typical in disordered systems with localized charge carrier states at low temperature.

The positive Seebeck coefficients $S$ for these films were in the $70-100 \mu \mathrm{V} / \mathrm{K}$ range indicating that the predominant charge carriers are holes. Previously, $S$ values for undoped $\mathrm{CuCrO}_{2}$ have been reported as $110-120 \mu \mathrm{V} / \mathrm{K} .{ }^{13}$ Our films display lower $S$ values but higher conductivity which may originate from native defects generated from $\mathrm{Cu}$ vacancies as the films are highly $\mathrm{Cu}$ deficient. Similarly we cannot exclude small amounts of unintentional dopants such as $\mathrm{Zn}$ or $\mathrm{Mg}$ from precursor impurities, though they are below the XPS detection limit $(\sim 0.5 \%)$. The polaronic nature of $\mathrm{CuCrO}_{2}$ has already been reported extensively ${ }^{33}$ and motivated by this we use the SPH model to estimate a mobility value. Within this model the Seebeck coefficient can be used as a direct mea- 


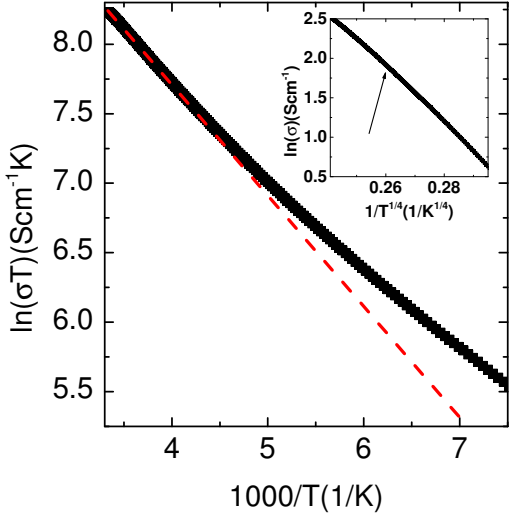

FIG. 6. The SPH model is used to fit the electrical data from $300-220 \mathrm{~K}$ as indicated by the red-dashed line. Below this the VRH model is more appropriate. The inset shows the conductivity as a function of temperature for this model.

sure of the fraction of occupied carrier sites ${ }^{7,9}, c$. This is related to the carrier concentration $p$ by $p=N c$, where the density of conducting sites $N$ can be calculated using the unit cell volume of the $\mathrm{CuCrO}_{2}$ crystal and the number of $\mathrm{Cu}$ atoms per unit cell $\left(2.5 \times 10^{22} \mathrm{~cm}^{-3}\right)$. From this $p$ it is possible to estimate a mobility of $6.4 \times 10^{-3}$ $\mathrm{cm}^{2} / \mathrm{Vs}$ for a sample with a conductivity of $12 \mathrm{~S} / \mathrm{cm}$ (the highest conductivity at room temperature for our films). The Hall mobility of $\mathrm{CuCrO}_{2}$ doped with $\mathrm{Mg}$ has been measured to be $0.042 \mathrm{~cm}^{2} / \mathrm{Vs}$ at room temperature for a sample with conductivity of $67 \mathrm{~S} / \mathrm{cm} .{ }^{34}$ Given that this is more conductive by an order of magnitude our estimated mobility is reasonable.

In summary, a nano-crystalline $\mathrm{Cu}$ deficient $\mathrm{CuCrO}_{2}$ phase has been grown with a high FOM $(350 \mu \mathrm{S})$ surpassing the best reported solution processed methods. ${ }^{18}$ This was achieved by spray pyrolysis at relatively low temperature $\left(\approx 345^{\circ} \mathrm{C}\right)$. Room temperature conductivities as high as $12 \mathrm{~S} / \mathrm{cm}$ without postannealing were observed. This growth method is scalable and low cost in comparison to alternative deposition methods. The film properties in terms of optical and electrical properties, and crystallographic phase are very similar to doped $\mathrm{CuCrO}_{2}$ despite the lack of any long range crystallographic order. Financial support by Science Foundation Ireland under grant No. 12/IA/1264 and grant No. 12/RC/2278 is gratefully acknowledged. This work was supported by the Higher Education Authority under the PRTLI scheme, cycle 5. Funding support from the Irish Research Council under grant no. GOI/PG/2013/445 is also acknowledged.

${ }^{1}$ Z. Chen, W. Li, R. Li, Y. Zhang, G. Xu, and H. Cheng, Langmuir 29, 13836 (2013)

${ }^{2}$ J. F. Wager, M. M. Valencia, J. P. Bender, B. J. Norris, H. Q. Chiang, D. Hong, L. N. Norris, T. V. Harman, S. Park, J. Anderson, C. H. Park, D. A. Keszler, J. Tate, H. Yanagi, M. Price, and R. L. Hoffman, in Cockpit Displays X, Proceedings of SPIE, Vol. 5080, edited by D. G. Hopper (Spie-Int Soc Optical Engineering, Bellingham, 2003) pp. 330-339.

${ }^{3}$ W. Yu, L. Shen, S. Ruan, F. Meng, J. Wang, E. Zhang, and W. Chen, Solar Energy Materials and Solar Cells 98, 212 (2012).
${ }^{4}$ Y. L. Wang, Q. L. Niu, C. D. Hu, W. J. Wang, M. He, Y. Zhang, S. T. Li, L. Z. Zhao, X. Wang, J. Xu, Q. X. Zhu, and S. H. Chen, Opt. Lett. 36, 1521 (2011).

${ }^{5}$ H. Kawazoe, M. Yasukawa, H. Hyodo, M. Kurita, H. Yanagi, and H. Hosono, Nature 389, 939 (1997).

${ }^{6}$ H. Hiramatsu, K. Ueda, K. Takafuji, H. Ohta, M. Hirano, T. Kamiya, and H. Hosono, J. Appl. Phys. 94, 5805 (2003).

${ }^{7}$ N. Mansourian-Hadavi, S. Wansom, N. H. Perry, A. R. Nagaraja, T. O. Mason, L.-h. Ye, and A. J. Freeman, Phys. Rev. B 81, $075112(2010)$.

${ }^{8}$ E. Arca, K. Fleischer, and I. V. Shvets, Appl. Phys. Lett. 99, 111910 (2011).

${ }^{9}$ L. Farrell, K. Fleischer, D. Caffrey, D. Mullarkey, E. Norton, and I. V. Shvets, Phys. Rev. B 91, 125202 (2015).

${ }^{10}$ R. Nagarajan, A. D. Draeseke, A. W. Sleight, and J. Tate, J. Appl. Phys. 89, 8022 (2001).

${ }^{11}$ S. Mahapatra and S. A. Shivashankar, Chem. Vap. Deposition 9, 238 (2003).

${ }^{12}$ S. H. Lim, S. Desu, and A. C. Rastogi, J. Phys. Chem. Solids 69, 2047 (2008).

${ }^{13}$ A. C. Rastogi, S. H. Lim, and S. B. Desu, J. Appl. Phys. 104 (2008).

${ }^{14}$ H. Y. Chen and C. C. Yang, Surface \& Coatings Technology 231, 277 (2013).

${ }^{15}$ U. Sidik, J. H. Kim, H. K. Kim, H. Y. Lee, and J. Y. Lee, Micro \& Nano Letters 9, 854 (2014).

${ }^{16}$ S. Narushima, H. Mizoguchi, K. Shimizu, K. Ueda, H. Ohta, M. Hirano, T. Kamiya, and H. Hosono, Advanced Materials 15, 1409 (2003).

${ }^{17}$ R. Wei, X. Tang, L. Hu, Z. Hui, J. Yang, H. Luo, X. Luo, J. Dai, W. Song, Z. Yang, X. Zhu, and Y. Sun, Chem. Commun. 50, 9697 (2014).

${ }^{18}$ M. Aksit, S. K. Kolli, I. M. Slauch, and R. D. Robinson, Appl. Phys. Lett. 104, 161901 (2014)

${ }^{19}$ E. Arca, K. Fleischer, and I. V. Shvets, The Journal of Physical Chemistry C 113, 21074 (2009).

${ }^{20}$ C. T. Prewitt, R. D. Shannon, and D. B. Rogers, Inorg. Chem. 10, 719 (1971).

${ }^{21}$ C. H. Ong and H. Gong, Thin Solid Films 445, 299 (2003).

${ }^{22}$ O. Aktas, K. D. Truong, T. Otani, G. Balakrishnan, M. J. Clouter, T. Kimura, and G. Quirion, J. Phys.: Condens. Matter 24, 036003 (2012).

${ }^{23}$ A. B. Garg, A. K. Mishra, K. K. Pandey, and S. M. Sharma, J. Appl. Phys. 116, 133514 (2014).

${ }^{24}$ A. A. Khassin, G. N. Kustova, H. Jobic, T. M. Yurieva, Y. A. Chesalov, G. A. Filonenko, L. M. Plyasova, and V. N. Parmon, Phys. Chem. Chem. Phys. 11, 6090 (2009).

${ }^{25}$ M. Amami, S. Smari, K. Tayeb, P. Strobel, and A. B. Salah, Mater. Chem. Phys. 128, 298 (2011).

${ }^{26}$ See supplemental material at [URL will be inserted by AIP] for XPS data of as grown and sputtered samples as well as unreacted precursors.

${ }^{27}$ M. C. Biesinger, L. Lau, A. R. Gerson, and R. S. C. Smart, Appl. Surf. Sci. 257, 887 (2010).

${ }^{28}$ H.-Y. Chen, K.-P. Chang, and C.-C. Yang, Appl. Surf. Sci. 273, 324 (2013).

${ }^{29}$ H. Sun, M. A. P. Yazdi, P. Briois, J.-F. Pierson, F. Sanchette, and A. Billard, Vacuum 114, 101 (2015).

${ }^{30}$ D. Li, X. Fang, Z. Deng, S. Zhou, R. Tao, W. Dong, T. Wang, Y. Zhao, G. Meng, and X. Zhu, J. Phys. D: Appl. Phys. 40, 4910 (2007).

${ }^{31}$ H. Yanagi, S.-i. Inoue, K. Ueda, H. Kawazoe, H. Hosono, and N. Hamada, J. Appl. Phys. 88, 4159 (2000).

${ }^{32}$ T. Okuda, N. Jufuku, S. Hidaka, and N. Terada, Phys. Rev. B 72 (2005).

${ }^{33}$ D. O. Scanlon and G. W. Watson, J. Mater. Chem. 21, 3655 (2011).

${ }^{34}$ M. O'Sullivan, P. Stamenov, J. Alaria, M. Venkatesan, and J. M. D. Coey, Journal of Physics: Conference Series 200, 052021 (2010). 


\section{Spray Pyrolysis growth of a high figure of merit, nano-crystalline, p-type Transparent Conducting Material at low temperature.}

\section{Supplementary information:}

\section{Effect of the cleaning procedure and sputtering on the XPS spectra.}

Prior to determining the $\mathrm{Cu} /(\mathrm{Cu}+\mathrm{Cr})$ ratio, it was necessary to remove traces of unreacted precursor precipitating after growth during sample cool down. All samples were sputter-cleaned using an $\mathrm{Ar}^{1+}$ ion gun operated at $500 \mathrm{~V}$ for 10 minutes with a sputter current of 2-3 $\mu \mathrm{A}$. Figure S1(a) shows the XPS spectra of the $\mathrm{Cu}$-precursor $\left(\mathrm{Cu}(\mathrm{acac})_{2}\right)$ itself, which matches previously published data on $\left(\mathrm{Cu}(\mathrm{acac})_{2}\right)$ [1]. The Copper region of as grown samples shows $\mathrm{Cu}$ in a +1 oxidation state with a mixture of the unreacted $\mathrm{Cu}$ precursor present (Fig S1(b)). After the initial cleaning step the precursor traces are removed, while the $\mathrm{Cu}+1$ signature of the oxide material remains unchanged (Fig S1(c)).

To investigate the variation of the $\mathrm{Cu} /(\mathrm{Cu}+\mathrm{Cr})$ ratio in the films, depth profiling was also performed. This was done using an $\mathrm{Ar}^{1+}$ ion gun operated at a higher voltage of $750 \mathrm{~V}$ with a sputter current of $8.5 \mu \mathrm{A}$. After sputtering steps (c)-(e) the $\mathrm{Cu}^{1+}$ and $\mathrm{Cr}^{3+}$ line-shapes do not change significantly. With XRR thickness measurements before and after sputtering the effective sputter rate was estimated to be $0.35 \mathrm{~nm} / \mathrm{min}$, while the initial cleaning step at lower voltage does not lead to a significant oxide removal.

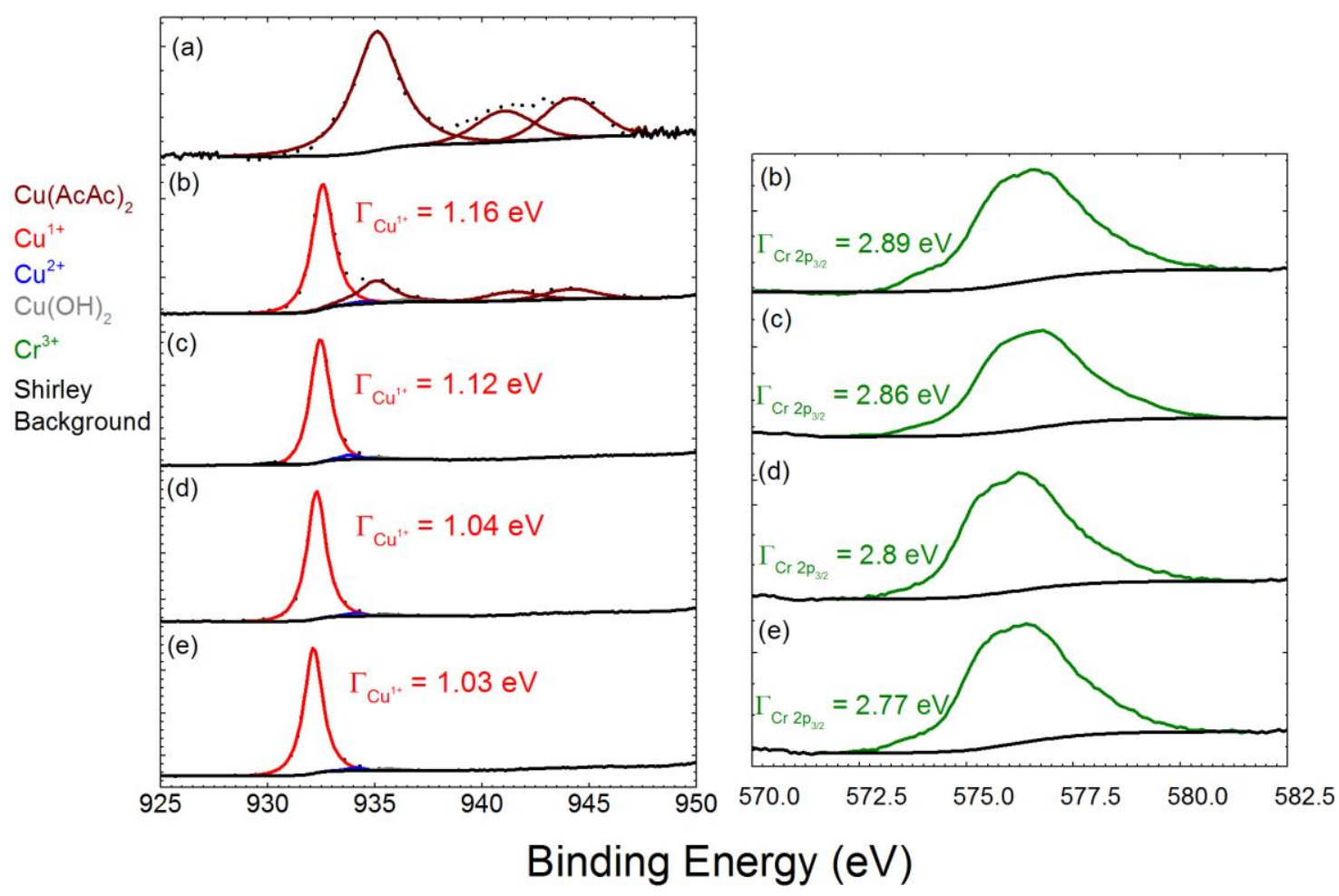

Figure S1 - XPS spectra of (a) the unreacted precursor. (b) shows the XPS spectra of both the Cu and Cr regions of the as received $\mathrm{Cu}$ deficient $\mathrm{CuCrO}_{2}$ sample. (c) is after typical cleaning conditions cleaned using an Ar ion gun operated at $500 \mathrm{eV}$ for 10 minutes with a sputter current of 2-3 $\mu \mathrm{A}$. (d) is after 33 minutes of depth profiling. (e) Depth profiling after 60 minutes.

[1] K. Okada, J. Kawai, A. Kotani, Triple-peak feature of Cu 2p x-ray-photoemission spectrum in copper acetylacetonate, Phys. Rev. B, 48 (1993) 10733-10738. 